\title{
AN ORGANIZATIONAL INFORMATION SYSTEMS ENHANCEMENT ADVICE UNIT (OISEAU)
}

Antoinette Kieback, Dornier GmbH, Friedrichshafen, Germany Joachim Niemeier, Fraunhofer IAO, Stuttgart, Germany

\begin{abstract}
This paper describes research work in the field of tools for choosing methods and tools to support the processes of planning, developing and implementing applications of information systems. A demonstration prototype for such a decision support tool has been elaborated and is presented here. This tool supports designers of information systems in finding an appropriate method or tool for their specific application out of a large database. By means of one specific scenario the capabilities of that tool, called OISEAU (Organizational Information Systems Enhancement Advice Unit), are evaluated.
\end{abstract}

\section{Introduction}

Over the last two decades, formal methods and tools have been introduced into the process of planning, developing and implementing applications of information technology. Today, the market is overcrowded with hundreds of incompatible information system engineering tools which are based on different methods. Therefore, the selection and evaluation of appropriate methods and tools for a specific application in a company requires a considerable effort and is itself a difficult and complex task. OISEAU (Organizational Information Systems Enhancement Advice Unit) is actually a demonstration prototype for a decision support tool to support the selection of appropriate methods and tools within the information systems engineering field. 
An investigation of the actual usage of methods and tools as undertaken in the ESPRIT II (European Strategic Programme for Research and Development in Information Technology) project HECTOR (Harmonized European Concepts and Tools for ORganizational information systems) often reveals the fact that the functionalities of the available and introduced methods and/or tools strongly determine the project scope and the project activities. In most of the cases the choice of methods and tools depends only on the specific knowledge about methods or tools and the past experiences of the analyst/designer. This cumulates often in solving the wrong problem. Tools for choosing methods and tools will be a major field in the future in order to react on the need of finding the appropriate method for a specific problem.

This paper presents a demonstration prototype for such a decision support tool as a medium to help designers of information systems searching for an appropriate method/tool by defining their development project and relating these definitions to the characteristics of the methods and tools described in a database. The capabilities of the OISEAU tool are shown using one specific scenario. The effect of altering the case study constraints produces shorter and longer lists of acceptable methods and tools.

OISEAU can be seen as a front-end of a methods and tools database. This allows to derive quantitative information about methods and tools in the information systems engineering field.

Chapter 1 illustrates the results of the HECTOR project, the frame for the development of the method and tools database and the decision support tool OISEAU. It shows the actual market situation in Europe of method and tools in the information system engineering area and relates the results of HECTOR and OISEAU to other known projects. The environment and the structure of the OISEAU prototype is outlined in chapter 1.4. By means of a case study, undertaken during the HECTOR project, the functionality of the demonstration prototype is illustrated in chapter 2 . The last chapter, chapter 3 is an outlook for possible future activities and development opportunities in that research field. 


\section{A Tool for Choosing Methods and Tools}

\subsection{Background}

The HECTOR project 2082 was part of the Office and Business Systems area of the ESPRIT II programme of the Commission for the European Communities. HECTOR was a one year explorative action. The term Organizational Informations Systems in the project name is defined as any socio-technical system which supports the work of an organization by facilitating the collection, flow and analysis of information within or between organizations. An organizational information system can include information technology, organizational structure, and work structure.

HECTOR was raised as the result of the common observation that existing methods and tools for information system improvement/development are incomplete, poorly integrated, often ineffective, and typically insensitive to the application environments. The purposes were to determine what is needed in the European marketplace, where opportunities lie to better meet these needs, and to present a framework within which these issues could be studied. A market survey undertaken during the project had provided an up to date assessment of the recent and potential uses of how to select from and make the most of what is available. For vendors of these products HECTOR maps out the opportunities for further development.

Tools for choosing methods and tools will be a major field in the future in order to react on the need of finding the appropriate method for a specific problem. Actually, this was a "gap" in the methods and tools market detected by the HECTOR market analysis as a development opportunity (see Pulst 1990).

In order to fill this gap two research prototypes have been developed, which were named SESAM and OISEAU. SESAM (Systematics for Elaboration, Selection and Assessment of Methods and tools) is a hypertext database of OIS (Organizational Information Systems) methods and tools described by the HECTOR Framework of Reference (FoR). OISEAU is a demonstration prototype for a decision support tool for the choice of OIS methods and tools out of the SESAM database. 


\subsection{A Step Beyond Existing Inventories of Methods and Tools}

The SESAM database contains information especially of methods and tools for OIS improvement which can not be found in existing inventories of available methods and tools. OIS methods are specific or generic methods/approaches covering one or more parts of the process of planning and controlling, building and introducing changes to OIS. We have identified eight streams of methods for:

- Project management

- System life-cycle support

- Socio-technical or organizational engineering

- Strategic planning

- Economic evaluation

- Configuration of equipment and software

- Management of changes

- Selection and implementation of software solutions

Our initial analyses have identified over 300 tools specifically designed to support one or more parts of the process of planning and controlling, building and introducing changes to OIS. About 250 methods and tools have then been described in the SESAM database, whereas 150 have been classified in such a detail that they are usable for the OISEAU prototype. The main classes listed below represent a highly fragmented and confused product market:

- Integrated project support environments

- Computer aided software/system engineering tools

- Analyst workbenches

- Modelling tools

- Diagraming tools

- Organizational Engineering tools

- Project management tools

- Portable common tools environment

Several surveys about OIS methods and tools are available on a commercial basis (see Ovum 1989, PSI 1989, Balzert 1989). The limitation of these surveys can be seen in its narrowed focus and the foundation of underlying structure 
for the description. A tools database should not be a paper dokument, like those studies above, because Information is obsolete the moment a document is printed. It is useful to use SESAM as an online system.

The focus is narrowed because normally only pure technical or even a specific subset of technical tools (e.g. lower CASE tools) are covered. Methods and tools designed to solve behavioural and organizational design problems can typically not be found in such surveys. The same statement is true for all business management aspects. It is interesting to recognize that the future mission of the System Design \& Engineering's mission in the 1991 ESPRIT workprogramme is seen in "Shift the focus of IT (Information Technology) away from technical excellence alone". Therefore, methods and tools including behavioural and organizational aspects are a prerequisite.

During the course of the HECTOR project, a database was designed to gather, characterize and review appropriate current methods and tools for OIS improvement. This database was structured according to the HECTOR Framework of Reference and provides a solid basis for harmonization of terminologies within which methods and tools can be viewed. HECTOR's framework was established to characterize:

- all of the relevant aspects of the environment in which information system development might take place,

- organizational information systems themselves,

- methods and tools that could be used to assist and support the system development process,

- ways of measuring the performance of each of these various entities, and

- the activities involved in information system improvement.

The major advance made through development of the Framework of Reference is the provision of a structure for relating the performance of OIS methods and tools to the environment in which they are used; by extrapolation when sufficient data has been gathered, this should provide means of predicting the performance of possible methods and tools proposed for new projects as an aid to choose between them. 


\subsection{Overview to Other Related Research and Development Activities}

There are several research and development projects which are considered to solve comparable problems and to undertake similar activities in some parts of the more global projects. These projects support the need for the development of tools to choose tools. Such kind of tools can be seen as an integral part of a future system engineering environment.

\section{- EUREKA Software Factory}

In the EUREKA Software Factory (ESF) project a wide range of methods and tools specific to life-cycle support in a variety of industries are covered. A meta model for process modelling has been used to generate requirements on notations for process modelling and on tools to support the various activities involved. The reference architecture contains a minimal kernel focussing on the 'plug in' of components and common aspects of process support. Implementation of components or reengineering of existing CASE tools in conformance with the generic ESF definitions continuous by extend the base of available factory components. The actual generation of factory process analysis, component selection, component adaptation and parameterization for component integration (see Thomas 1990).

\section{-ATMOSPHERE}

The ATMOSPHERE project is an ESPRIT II Technology integration project. A specific workpackage in this project addresses the more fundamental conceptual and methodological issues of system engineering and rationalises the choices for certain methods in the overall system engineering process. In the ATMOSPHERE System Engineering Model ADEM special consideration is given to the methods and tools supporting the Life-Cycle Process, the Quality Assurance Process and the Management Process. The combination of methods is felt to be of major relevance for industry. Work in the development phase of ATMOSPHERE will concentrate on the issue of method-composition (see Grange 1990). 
-Software Factory Integration and Experimentation

The Software Factory Integration and Experimentation (SFINX) project is as well an ESPRIT II Technology integration project. Some specific objectives of the project are, to verify and promote the usability and availability of PCTE as basis for software factory implementation, to derive, from practical experimentation, mechanisms allowing the integration of already existing tools in a software factory, and to establish a basis for tool analysis and characterisation. The last point is the relation to the OISEAU and SESAM development, where possible connections for future developments could be (see IPS 1990).

\subsection{The OISEAU Tool}

\subsubsection{The Underlying Decision Situation}

In daily practice the search for an appropriate method and/or tool is seen very time consuming and complex, depending on the scope of the questions to be answered:

- Does it cover the life cycle phases that are important for system success? Does it cover the relevant subsystems (e.g. organizational design, if appropriate)?

- Is it flexible? Can it be adapted to our organization's needs? Will it accommodate possible changes in system development such as switching to prototyping after a preliminary analysis has been conducted?

- Is the language (graphical and verbal) easy to learn and easy to use? Does it permit to describe all of the details of a system, needed to know, to understand it sufficiently so that it can be improved?

- If the method provides only partial coverage of the situation, is it compatible with the other methods that will be used alongside it?

- Are there tools supporting the methodology or method? Are those tools 
compatible with each other? Does the expected benefit from their use (higher productivity, better quality results) exceed the various costs (cash outlay, time required to learn to use them, user acceptance)?

This of course is not a complete list of questions, it can only give a taste of the complexity of the decision situation. Fluctuating and conflicting requirements cause additional problems.

\subsubsection{The OISEAU Users}

OISEAU is today a demonstration prototype for a decision support tool which supports various users. In its full form it would be intended for four types of users:

- The project manger or manager of an OIS user department who wants advice on what would be involved in carrying out possible improvements to the OIS, what methods and tools are available, and which might suit the environment best;

- A consultant employed to assist a user manager to carry out an OIS improvement project;

- A manager in a tool development organization, seeking information on gaps and defects in the OIS tool market which the organization might remedy;

- A researcher interested in investigations in the OIS methods and tools area.

\subsubsection{The OISEAU Cycle}

Existing system engineering models do not provide enough insight into the real system development processes to guide the selection and evaluation of methods and tools. A typical statement often heard is: "The conditions surrounding our project would not let us work from our model". Therefore, the HECTOR consortium proposed with the HECTOR Framework of Reference (FoR) a mean to understand the system development process. In contrast to other frameworks 
the FoR provides insight into the environmental conditions and the organizational context of system development.

Based on this framework there are essentially three categories of data relevant to the operation of OISEAU.

- One covers the description of a project's environment, which relates the environment to methods and tools.

- Another category details all of the available methods and tools. This is SESAM.

- The third contains data on the performance of methods and tools in defined environments obtained from completed projects.

All of these data are based on HECTOR's Framework of Reference and should be the structure of the central system database, not developed for the prototype.

The operation of OISEAU is fairly straightforward (see figure 1), though technically far from being simple. The user would enter the details of the proposed project into the system. This would include descriptions of:

- the existing OIS,

- the organizational environment (both internal and external) in which the improvement is to take place,

- the nature of the problem(s) to be resolved,

- constraints affecting the project (e.g. budget, deadlines) and the like.

All of these data would be entered by using the FoR in terms of the variables (characteristics) used and their measurements.

OISEAU would now try to match the current environment with those in its historical database (the database containing how well various methods and tools have worked in different environments in past projects). It would examine similar environments to identify those methods and tools which have performed well, and then deliver a list of methods and tools that would be acceptable (rank ordered when the system has reached that level of sophistication). A choice would then be made by the user of specific method(s) and tools to be used, related to the current project development phase. 


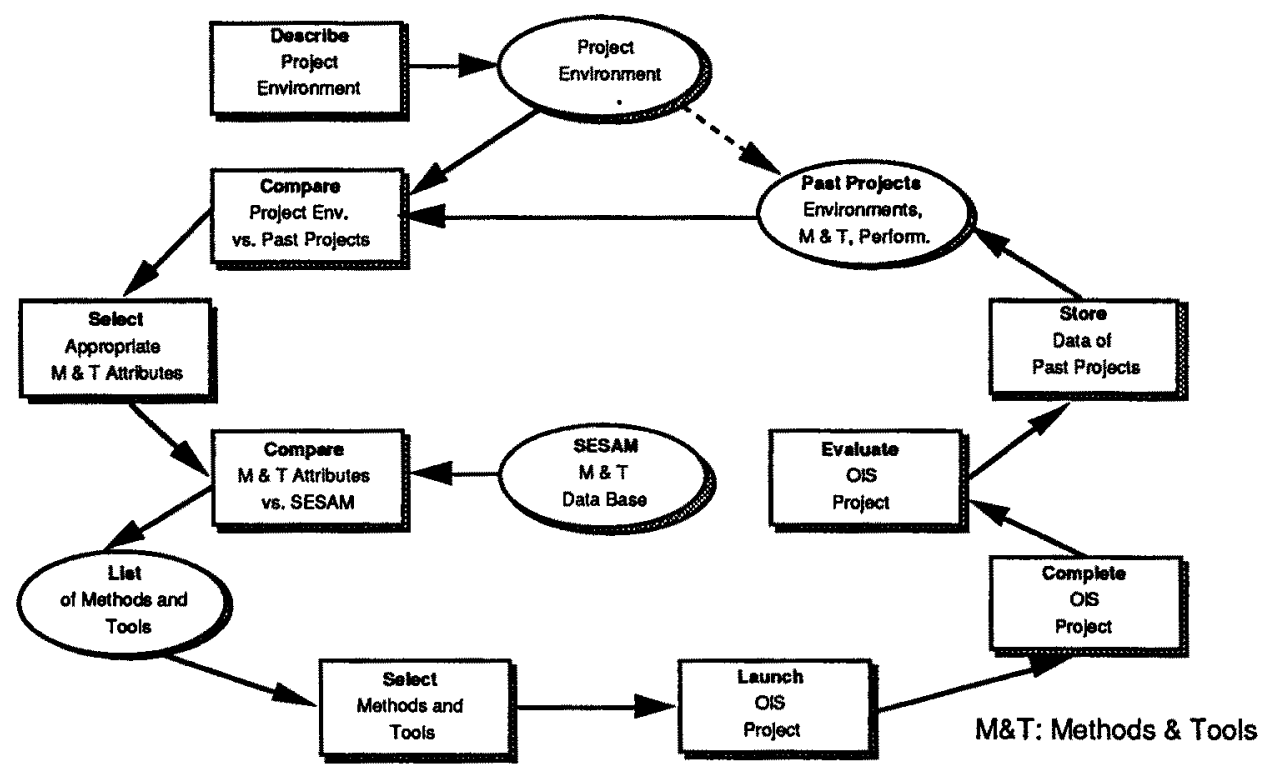

Fig. 1: The OISEAU Cycle

To continue the cycle, the project would be launched using the method(s) and tools chosen. After its completion an evaluation would be conducted, especially with respect to methods and tools as far as OISEAU is concerned. Their performance, along with the original environmental data and the methods and tools chosen, would be stored in the past projects database, to be used the next time a project is in the formulation stage.

\subsubsection{The OISEAU Demonstration Prototype}

At present OISEAU exists as a demonstration prototype, developed object oriented using SuperCard on a Macintosh computer. The philosophy of SuperCard is to represent all screens by cards, with mouse sensitive buttons and graphical backgrounds. This user friendly interface is used to illustrate the OISEAU functional model guiding the user through OISEAU, and visualize the FoR for inserting project data. In the SESAM database a tool or method is represented by a card containing all information. There are up to now 150 entries upon which OISEAU may trace a subset. 
This demonstration prototype actually covers that part of OISEAU, that describes the OIS development project, but just with the most important structures of the FoR, and ends up with a list of methods and tools found in the SESAM database. There is a lack of data on the performance of methods and tools in various environments. What is implemented, however, is a list of keywords connected to each method and tool in the database that indicates the possession of the attributes represented by those keywords. Thus the user can describe the various aspects of methods and tools that are important to an OIS project, and the system will scan the database to see which approach meets the stated requirements/constraints. This is done by means of a predefined check list shown on the screen of the computer, so that all the user has to do is to mark those attributes he seeks. At this point everything available are yes/no measures, which is some distance from the intended long range objectives.

The functional model of the OISEAU demonstration prototype is represented in the following picture.

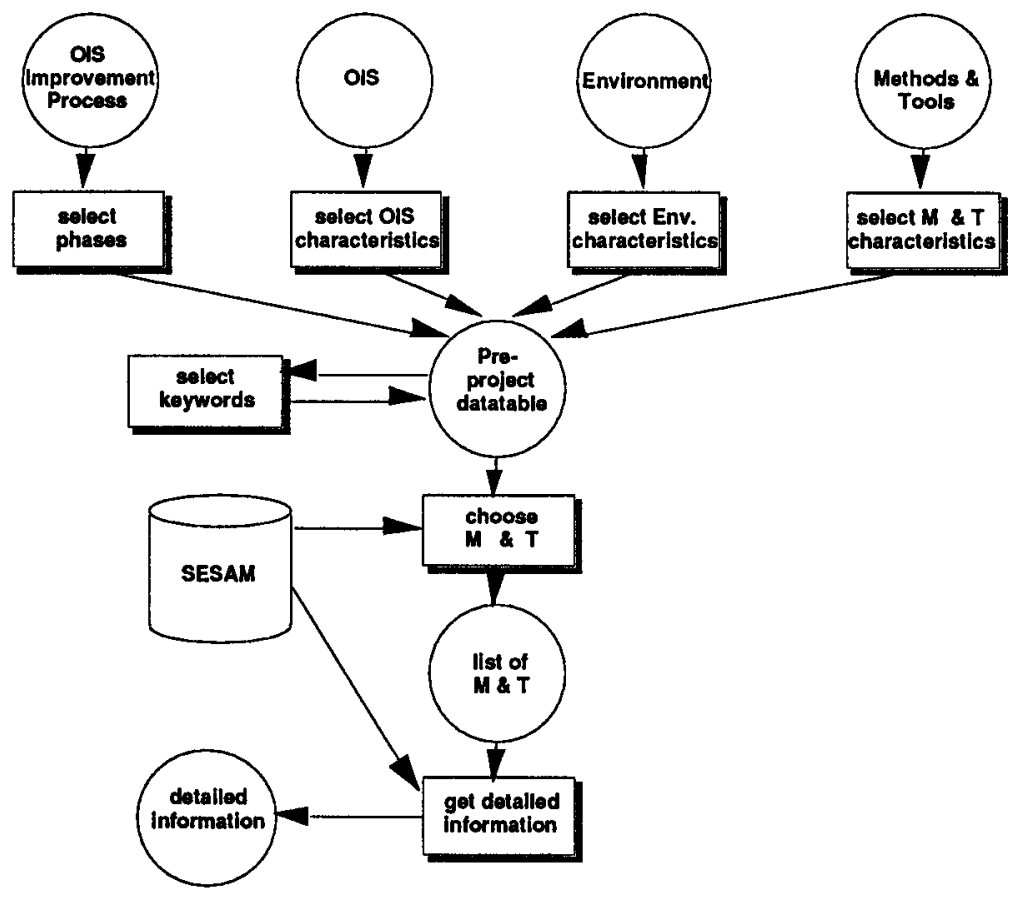

Fig. 2: The OISEAU Demonstration Prototype 
Circles are representing data structures and the SESAM data base is represented by a drum. Rectangles represents processes. OISEAU consists of four parts implicitly shown in figure 2 :

- Definition of the OIS project characteristics

- Selection of requirements out of the defined project characteristics using keywords

- Choice of methods and/or tools according to the requirements

- Precision of a method or tool of the choice list, containing the chosen methods and tools

While the prototype does not provide a mean for ranking methods and tools as such, basically because there are no data to do so, it does have an interesting feature which permits an indirect ranking of sorts. The user can add or subtract requirements and constraints according to their relative importance. The greater the number of limitations, the fewer will be the number of appropriate methods and tools. Obviously the reverse is true as well. Thus one can add constraints until there is only one method that satisfies them, or gradually relieve them to see what additional methods are now acceptable.

\section{Is OISEAU useful? - Tracing a Case Study}

A decision support tool, supported by a comprehensive database of OIS methods and tools would improve the process of selection and evaluation of organizations acquiring these products. This section is concentrating on the process of how methods and tools have been selected in a specific company and how this process could have been supported by OISEAU. The information about the real process was available in form of an Alitalia in-depth HECTOR case study (Manfredi 1990). Reveals OISEAU other possible solutions or will the Alitalia decision be supported? What happens if the project scope is changed, e.g. via including organizational design aspects, or if the list of requirements is reduced or enlarged? A variety of events can cause volatility and conflict in requirements: Will this have consequences on the Information Systems Engineering Environment? 


\subsection{The case study - Choice of a OIS Toolkit for Alitalia}

Alitalia has a system development department, developing information systems for their own use. The case study mainly covered the reorganization of that particular department. The introduction of an OIS toolkit was seen as one measure for the improvement of effectiveness and efficiency of the information system development process.

\subsubsection{Pre-Project Situation}

The existing Alitalia Information Systems have previously been designed and implemented by a methodology developed in house without any computerbased support tool. Different problems occured using that methodology in several development phases.

- the methodology outputs were not understandable

- no central repository was available

- serving different repositories caused extra work to maintain, with redundancy and inconsistencies

- low productivity of the organizational staff

- complex maintenance of the system

The Alitalia management decided to reorganize the system development department using computer supported methodologies, mainly to increase the productivity of the organizational staff. Using a centralized repository/encyclopedia on a mainframe system was one of the most important requirements for the choice of an appropriate computer based methodology. Alitalia started a pilot project which influenced the management decision for the major reorganization.

\subsubsection{The Method and Tool Selection Process}

A market survey has been undertaken by Alitalia to select the most suitable product. Surveys have been established to find the optimal computer based tool 
supporting three different environments:

- Designer's workbench

- Programmer's workbench

- Integration aspects

The following methods and tools requirements have been expressed in the case study. For the OISEAU prototype, some of them have to be transformed into keywords.

\begin{tabular}{|c|c|c|c|}
\hline & $\begin{array}{c}\text { Designer's } \\
\text { Workbench } \\
\text { Analysls } \\
\text { Tool } \\
\end{array}$ & $\begin{array}{c}\text { Programmer's } \\
\text { Workbench } \\
\text { Code } \\
\text { Generators }\end{array}$ & $\begin{array}{l}\text { Integrated } \\
\text { Products }\end{array}$ \\
\hline Functional analysis & 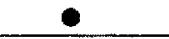 & & e \\
\hline Data analysis & e & & e \\
\hline Encyclopedia/Repository & 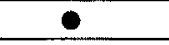 & 0 & 0 \\
\hline Prototyping & 0 & - & \\
\hline PC utilization & - & - & e \\
\hline Mainframe utlization & - & 0 & 9 \\
\hline HW Constraints & 0 & - & e \\
\hline SW Constraints & & - & - \\
\hline Symbollc code generator & & 0 & $\mathbf{0}$ \\
\hline Compatibllity with internal Standard & & e & - \\
\hline Metalanguage avallabllity & & ○ & $\bullet$ \\
\hline
\end{tabular}

Fig. 3: $\quad$ Methods and Tools Requirements

The full case study report contains additional information which can be used in the extended OISEAU execution (Manfredi 1990).

\subsubsection{Post-Project Evaluation}

Alitalia has evaluated ten products in detail and finally chosen the IEW product, a CASE tool, based on the Information Engineering Methodology by James Martin. The tool supports planning, analysis, and design phases of the system life cycles. The IEW product, satisfying most of Alitalia's goals, supported the pilot project in an ideal form achieving suitable results, so that from the management perspective IEW was chosen as a standard for the organization. 
Based on this test scenario the following chapter describes the experiences gained by acting in the role of OISEAU users, here the Alitalia decision makers. It will be described by graphics showing some screens of different stages of the use of OISEAU.

The user of the OISEAU demonstration prototype will act as a designer or project manager of the Alitalia development project, those persons responsible for the reorganization of the system development department at Alitalia. They will describe the specific project characteristics in the first run using the OISEAU system. Then they will specify the most important requirements they strongly are interested in as selection criteria for the desired methods and tools stored in the database SESAM. Depending on the type and the amount of criteria more or less methods and tools will be offered to them in an alphabetically ordered list. Now they have the possibility to get more detailed information on specific methods or tools of the offered list. When they are unsatisfied with the resulted list, they may now change the choice requirements (the importance of requirements is not always equal) and perhaps get a different list as output.

\subsubsection{Method and Tool Selection using OISEAU}

Following the data flow of the OISEAU prototype model in figure 2, the designer is defining the characteristics of the Alitalia project environment. The OISEAU user is guided by the software system through four description structures:

- OIS Improvement Project

- OIS Characteristics

- Project Environment

- Method and Tool Characteristics

The first is representing the dynamic and the other three together the static model. The decision maker will be guided through the hierarchies of those models. Via the dynamic model the process of describing the project 
characteristics is described in the following. Figure 4 represents the relations between processes and data. In a hierarchy the processes are refined until a level of basic actions is reached. A subset of these action boxes have little, mouse sensitive squares connected, which indicate this action as a keyword (see figure 4). Clicking in that square means, that a special keyword is important for the choice of methods and tools and characterizes therefore the specific project. It was an important requirement for the Alitalia toolkit to support situation analyses, so the designer is clicking on the little square connected to the box containing "Analyze Situation" in the dynamic model, to define the project with this keyword.

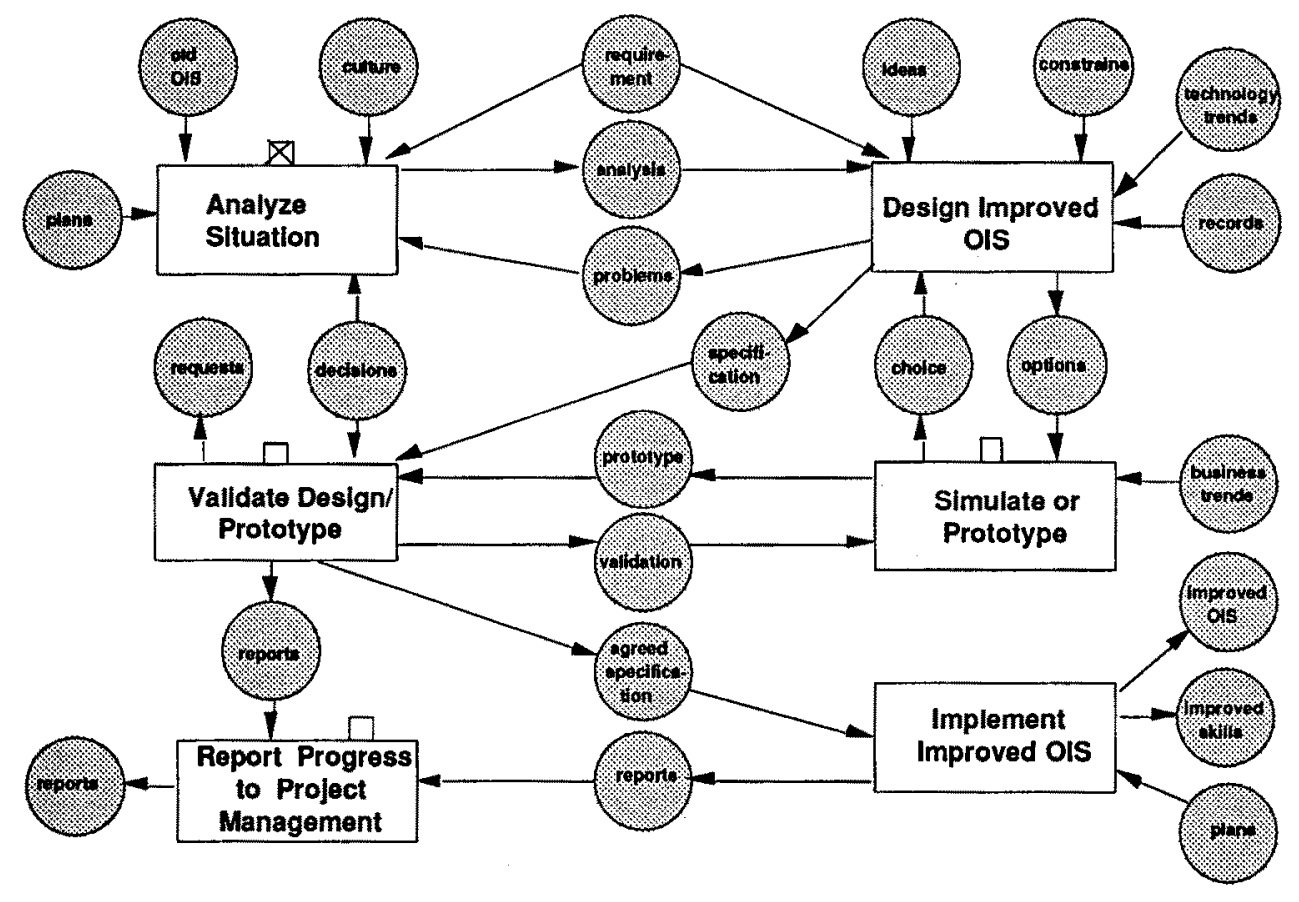

Fig. 4: Alitalia Project Definition in the Process Model

Similar to the dynamic model of the "OIS Improvement Process" the decision maker can enter desired characteristics into the other three static models. 
For Alitalia the following OIS project characteristics have been defined:

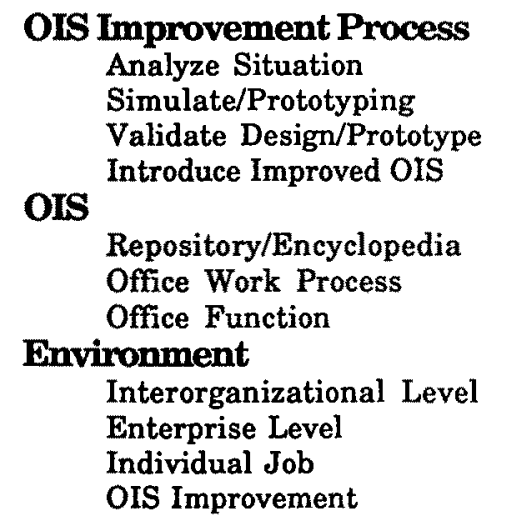

\author{
Methods and Tool \\ Data Processing \\ Office System \\ Business Objectives \\ Technical Performance \\ Social Objective \\ Ease of Use \\ Flexibility \\ Reusability of Results \\ Process \\ Information \\ Natural Language \\ Structured Language \\ Computerbased Tool \\ IEW Methodology \\ Method Supported \\ Prototyping Facility \\ IBM-Mainframe \\ IBM-PC \\ Other Hardware
}

For the OISEAU prototype not all keywords from the HECTOR Framework of Reference have been implemented, because of the short time frame in the HECTOR project. 70 out of over 350 keywords are integrated in the prototype.

The keywords, which previously were defined by the designer to characterize the OIS project, are the basis for the selection of constraints and/or requirements upon which the methods and tools will be chosen. These characteristics have been inserted into four data tables corresponding to the four description structures. These tables contain two rows of boxes on the right hand side, the left row is representing the characteristics, visualizing them to the designer but will not directly be taken into account for the choice process, and the second the constraints upon which the choice will take place (see figure 5).

OISEAU is actually able to choose methods and tools for the maximum of 10 constraints, which normally is more than decision makers tend to take into account in real situations. The number of keywords already selected in the other three tables are shown in small boxes near the names of those tables. 
Project: alitalia

\begin{tabular}{|c|c|}
\hline $\begin{array}{l}\text { Activities } \\
\text { Business Strategy } \\
\text { OIS Strategy } \\
\text { Prepare Project } \\
\text { Executive OIS Project } \\
\text { Choose Method } \\
\text { Project Success Factors } \\
\text { Manage Project } \\
\text { Make OIS Improvement } \\
\text { Analyze Situation } \\
\text { Simulate/Prototype } \\
\text { Validate Design/Prototype } \\
\text { Design Improved OIS } \\
\text { Design Organization } \\
\text { Specify Tech. Asp. of Chosen Option } \\
\text { Design Hardware } \\
\text { Design Software } \\
\text { Implement Improved OIS } \\
\text { Plan Introduction of Reorganization } \\
\text { Inform Users } \\
\text { Aquire Hardware } \\
\text { Integrate and Test Software } \\
\text { Educate and Train Users } \\
\text { Introduce Improved OIS } \\
\text { Report Progress } \\
\text { Evaluate Performance } \\
\text { Assess Project }\end{array}$ & 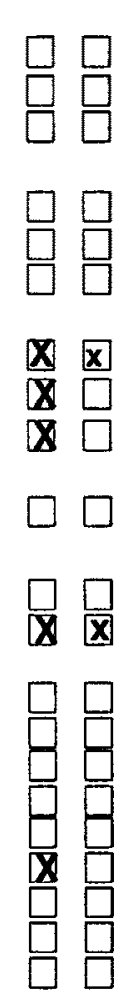 \\
\hline
\end{tabular}

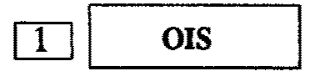

1

Environmen

6

Method/Too

Fig. 5: Selected Constraints

Starting the action "Choose methods and tools" (see figure 2) SESAM will be directly accessed. The keyword field of the Bibliographic Cards of all SESAM entries will be searched for the selected requirements and the names of the methods/tools will be listed, as can be seen in the following figure. This List is containing all methods/tools names found for the constraints of the Alitalia case.

Having the list of chosen entries, one of them can be picked to get more detailed information. For that purpose OISEAU is directly showing the entry in the SESAM database. Figure 7 shows the bibliography information of a selected SESAM entry. In addition more descriptive details are available in the analysis part of SESAM. 


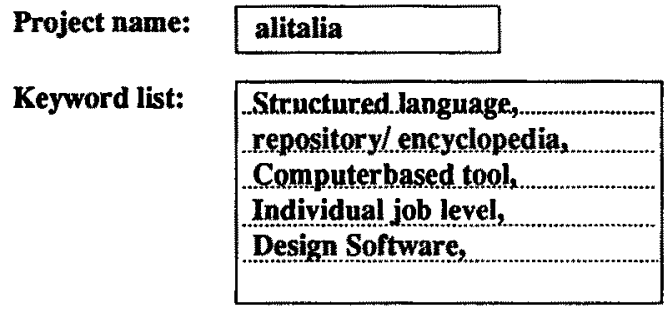

List of Methods, Methodologies and Tools in SESAM, matching the keywords

\begin{tabular}{|l|l|}
\hline AD/CYCLE (Application Development Cycle) \\
Analyst/Design Toolkit \\
Auto-Mate Plus \\
EPOS \\
EXCELERATOR \\
FOUNDATION \\
IEF (Information Engineering Facility) \\
IEW (Information Engineering Workbench) \\
INNOVATOR - advanced software tools (version 3.1.) \\
Oracle Case \\
Predict Case \\
ProMod \\
Teamwork
\end{tabular}

Fig. 6: List of Methods and Tools for Alitalia

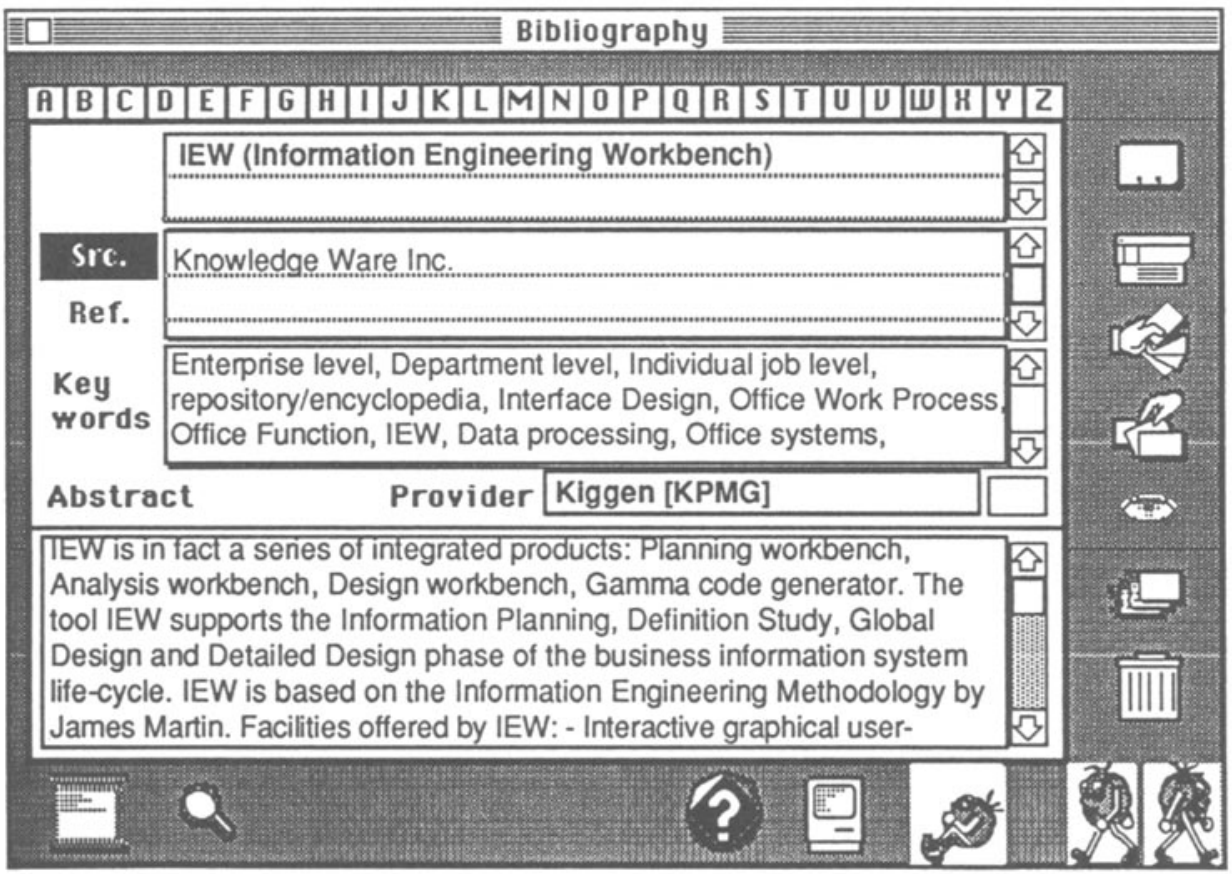

Fig. 7: $\quad$ Display of a SESAM Entry 
Using the content of SESAM more methods and tools are preselected for the Alitalia requirements than IEW only, even if the choice is restricted to the constraint to use the IEW-methodology. There exist some tools, based on the methodology of IEW, which then are listed as well.

\section{Discussion and Conclusion}

The HECTOR Market Analysis has shown that a good initial choice of methods and tools is very important presupposed for the success of a project. A wrong initial choice often leads to the failure of a project or at least to higher costs.

The prototype allows a first rough selection of appropriate methods and tools on basis of a maximum of ten project relevant criteria out of 70 . It is important to notice that even the prototype can handle more criteria in contrast to the number of criteria applied in a "normal" human decision making process. Results from the HECTOR market analysis show that only one or two criteria are typically used for the selection of methods and tools. For the final choice the decision maker can investigate the preselected methods and tools in more depth, e.g. via personal contact to a vendor.

Additional question will be raised like:

- Has the tool vendor an office located in the same region?

- What kind of support is offered by the local office?

- Will the method/tool find acceptance in our organization?

- Is the method/tool already known in our organization?

- Does the method/tool fit to political organizational constraints?

- Which experiences has the project manager?

It is obvious that these factors also strongly determine the final choice. But these factors differ from company to company. It is important to notice that decision relevant information about these factors only can complement the preselected decision information produced using OISEAU but never substitute them - as often observed in practice. 
Using OISEAU the possible solution space is widened. At the same time the decision making process is more efficient: A broader spectrum of possibilities can be checked. A known method/tool is very often chosen, but normally the problem awaiting for a solution is then adapted to the functionality of that chosen method/tool. This leads in most cases to a situation, in which the wrong problem is solved. The effect of altering the Alitalia constraints produces shorter and longer lists of acceptable methods and tools. This provides insights in the robustness of solutions.

Another analysis result is that the method/tool concept needs a significant adaptation during the project execution. The OISEAU prototype using Alitalia shows, that other methods/tools could as well have been useful, right from the beginning.

\section{$3 \quad$ Next Steps and Longer Term Issues}

Starting from the prototype, OISEAU now needs to be refined with the following improvements in a longer term:

- use improved FoR as a basement, utilizing sophisticated domains containing weights for the keywords,

- describe and evaluate the environment where the method/tool has been used,

- provide a search mechanism using all defined keywords and ordering the result list according to the best choice and indicating, why one method/tool is better than another one,

- establish an online help with keyword definitions,

- take into account the phase, in which the project actually is searching for a tool, to be able to use OISEAU in the following phase, without necessarily describing the project again,

- take into account experiences from previous OIS-projects, by storing the environmental data the methods/tools chosen and information about the evaluation of the method/tool used in that environment.

The most important steps to be taken are enhancing the conceptual model of SESAM, to cover performance data, and gathering a sufficiently rich database on the performance of methods and tools in various environments so that 
OISEAU can operate as proposed. The maintenance of a database like SESAM is a time consuming task, in a rapidly changing market, and has to be coordinated among several organizations. For such a process several aspects have to be taken into account:

- methods and tools have to be tested by a confident unit

- rapidly changing market in the method and tools area

- marketing slogans emphasizes the positive method and tools criteria

- vendors should automatically inform the maintenance team about upgrades

- widely contact to potential method/tool users.

To allow features meantioned above, it is obvious, to use implementation facilities of knowledge based systems, especially, when implementing the use of past project information.

\section{Acknowledgements}

The results presented in this report are mainly derived from the HECTORproject, wherein six European countries contributed their work. We thank BIFOA, Cap Gemini Innovation, CRAI, Delga Internacional S.A., FhG IAO, IOT, KPMG Peat Marwick McLintock, and PA Consulting Group for their research work on the European market, CRAI, Dornier, FhG IAO, and PA for their work on the FoR and the development of SESAM and OISEAU. We also like to thank the University of Jyväskylä and East Anglia for their contribution to the Market Analysis and the FoR. All partners supported in gathering and inserting data on methods/tools into the SESAM database. 


\section{References}

Balzert 1989: Balzert, H.: CASE - Systeme und Werkzeuge, Band 7, Reihe: Angewandte Informatik, BI Verlag, Mannheim 1989.

Grange 1990: Grange, J.-L., and Obbink, H.: An overview of the ATMOSPHERE Project. Advanced Tools and Methods in Heterogeneous, Extensible, Real Environments, Proceedings ESF ‘90 Seminar, Berlin 1990.

IPS 1990:

IPS Synopsis, ESPRIT II, CEC

Manfredi 1990: Manfredi, F., Gaudenzi, F., Orlando, G., Tortorici, P.: HECTOR Market Assessment, Italian Country Report, 1990.

Ovum 1989:

Rock-Evans, R., and Engelien, B.: Ovum, Analysis Techniques for CASE: a detailed Evaluation, Volume 1 Ovum Ltd, London, 1989.

PSI 1989:

Woschinski, S. and Warner, A.: PSI, Softwareentwicklungswekzeuge im Vergleich, PSI, Berlin, 1989.

Pulst 1990:

Pulst, E., Hawgood, J., and Niemeier, J.: Development Opportunities, HECTOR Report, 1990.

Thomas 1990: Thomas, R.E., Fernstoem, C., Hesse, O.: ESF-Project Overview 1990, Proceedings ESF '90 Seminar, Berlin 1990. 